\title{
Characterization of Corrosion Films on Austenitic Stainless Steels Exposed to High- Temperature Deaerated Water
}

\author{
Jonas K. Heuer $^{1}$ and Matthew J. Stiger ${ }^{1}$ \\ 1. Naval Nuclear Laboratory, Plant Materials and Laboratory Services, West Mifflin, PA, USA.
}

Austenitic stainless steels are well known for their passivity and corrosion resistance in hightemperature water, and these characteristics made them a material of choice for the first water-cooled nuclear reactors [1]. A significant number of studies have since been performed on the corrosion films that form on 304 stainless steel in high-temperature water [1-3], but less information is available on Mobearing austenitic stainless steels. This paper therefore provides a characterization and a comparison of the corrosion films on 304, 317L, 904L, and AL-6XN® stainless steels. Oxide films were grown on these materials in the same 3200 hour autoclave exposure in $260^{\circ} \mathrm{C}$ deaerated water. Total-corrosion measurements were found to vary by approximately a factor of two as determined from the difference between initial-coupon and final-descale masses. The 304 and 317L exhibited higher corrosion values of 24 and $27 \mathrm{mg} / \mathrm{dm}^{2}$ respectively, and the 904L and AL-6XN@ exhibited lower corrosion values of 12 and $11 \mathrm{mg} / \mathrm{dm}^{2}$ respectively.

The corrosion films on all four stainless steels were characterized by Transmission Electron Microscopy (TEM) in an FEI Tecnai F20 microscope. Energy Dispersive X-ray (EDX) spectra were acquired from features of interest in scanning-transmission mode using an Oxford Instruments X-Max ${ }^{\mathrm{N}}$ 100TLE silicon drift detector, and selected-area electron diffraction patterns were recorded in transmission mode to identify the crystal structure of the corrosion films and underlying base metals. TEM foils of the corrosion films were prepared using a focused ion beam liftout method in an FEI Nova NanoLab dualbeam system. The oxide films on all materials were found to have a dual-layer structure consisting of an outer oxide layer composed of faceted crystallites and an underlying inner oxide layer (Figure 1). The inner oxide layer in each material is more uniform in thickness than the outer oxide layer, but the thicknesses of both oxide layers vary among the four stainless steels. The total thickness of the combined dual layers is greater in 304 and 317L (1600 and $830 \mathrm{~nm}$ respectively) and is lower in 904L and AL-6XN@ (400 and $410 \mathrm{~nm}$ respectively). In addition, the inner and outer oxide layers each make up approximately half of the total oxide thickness on each material.

The inner oxide layers have a crystal structure and composition consistent with $(\mathrm{Fe}, \mathrm{Ni})(\mathrm{Fe}, \mathrm{Cr})_{2} \mathrm{O}_{4}$ spinel. $\mathrm{Cr}$ and $\mathrm{Fe}$ are the primary cations in this structure, but lower levels of $\mathrm{Ni}, \mathrm{Mn}$, and Mo are also present. This oxide layer has an ultrafine grain size and is enriched in $\mathrm{Cr}$ and depleted in $\mathrm{Fe}$ relative to the underlying base metals. EDX line scans show that $\mathrm{Cr}$ and $\mathrm{Fe}$ levels vary within the films by approximately 13-14 wt.\% from region to region. In addition, there is a notable gradient in $\mathrm{Cr}$ and $\mathrm{Fe}$ levels across the inner oxide in $317 \mathrm{~L}, 904 \mathrm{~L}$, and $\mathrm{AL}-6 \mathrm{XN} 囚$ that is not present in 304 . Cr levels decrease and Fe levels increase within this gradient from the base metal to the outer oxide. Mo is also incorporated into the inner oxide in $317 \mathrm{~L}, 904 \mathrm{~L}$, and AL-6XN@; it is present at concentrations between $8-12 \mathrm{wt} . \%$ in the oxide adjacent to the base metal, and it transitions down to negligible levels part way through the inner oxide layer. Mo is not detected in the inner oxide in 304 which is also not present in this base metal.

The outer oxide crystallites on all materials have a crystal structure and composition consistent with a $(\mathrm{Fe}, \mathrm{Ni}) \mathrm{Fe}_{2} \mathrm{O}_{4}$ spinel. Ni levels vary from 4-21 wt.\% among samples and increase with the Ni content of 
the underlying base metal. Similarly, Fe/Ni ratios in the outer oxide crystallites also track those in the base metals which suggests that the outer oxide layer is formed at least in part by diffusion of $\mathrm{Fe}$ and $\mathrm{Ni}$ ions out of the base metals to form oxide crystallites. This hypothesis is also supported by the observation that the outer oxide layers for each alloy are approximately the same thickness as the inner oxide layers, the depletion of $\mathrm{Fe}$ and $\mathrm{Ni}$ from the inner oxide layer, and the corresponding enrichment of $\mathrm{Fe}$ and $\mathrm{Ni}$ in the outer oxide layer.

The base metals adjacent to the oxidized surface in all materials have a sub-grain structure much finer than that present in the bulk. This sub-grain structure is consistent with highly-deformed material associated with the machined coupon surfaces, and the base metal grains have the fcc austenite structure. A layer enriched in $\mathrm{Ni}$ is also present at the interface with the inner oxide layer. This is attributed to a selective oxidation process in which $\mathrm{Ni}$, being a more noble metal than $\mathrm{Fe}$ or $\mathrm{Cr}$, is not incorporated into the oxide layer and is subsequently concentrated in the metal near the oxide/metal interface [4].

\section{References:}

[1] SE Ziemniak and M Hanson, Corrosion Science 44 (2002) 2209.

[2] K Wang et al, Materials and Design 82 (2015) 155.

[3] Y Asakure et al, Corrosion 45:2 (1989) 119.

[4] S Lozano-Perez et al, Metallurgical and Materials Transactions E 1 (2014) 194.
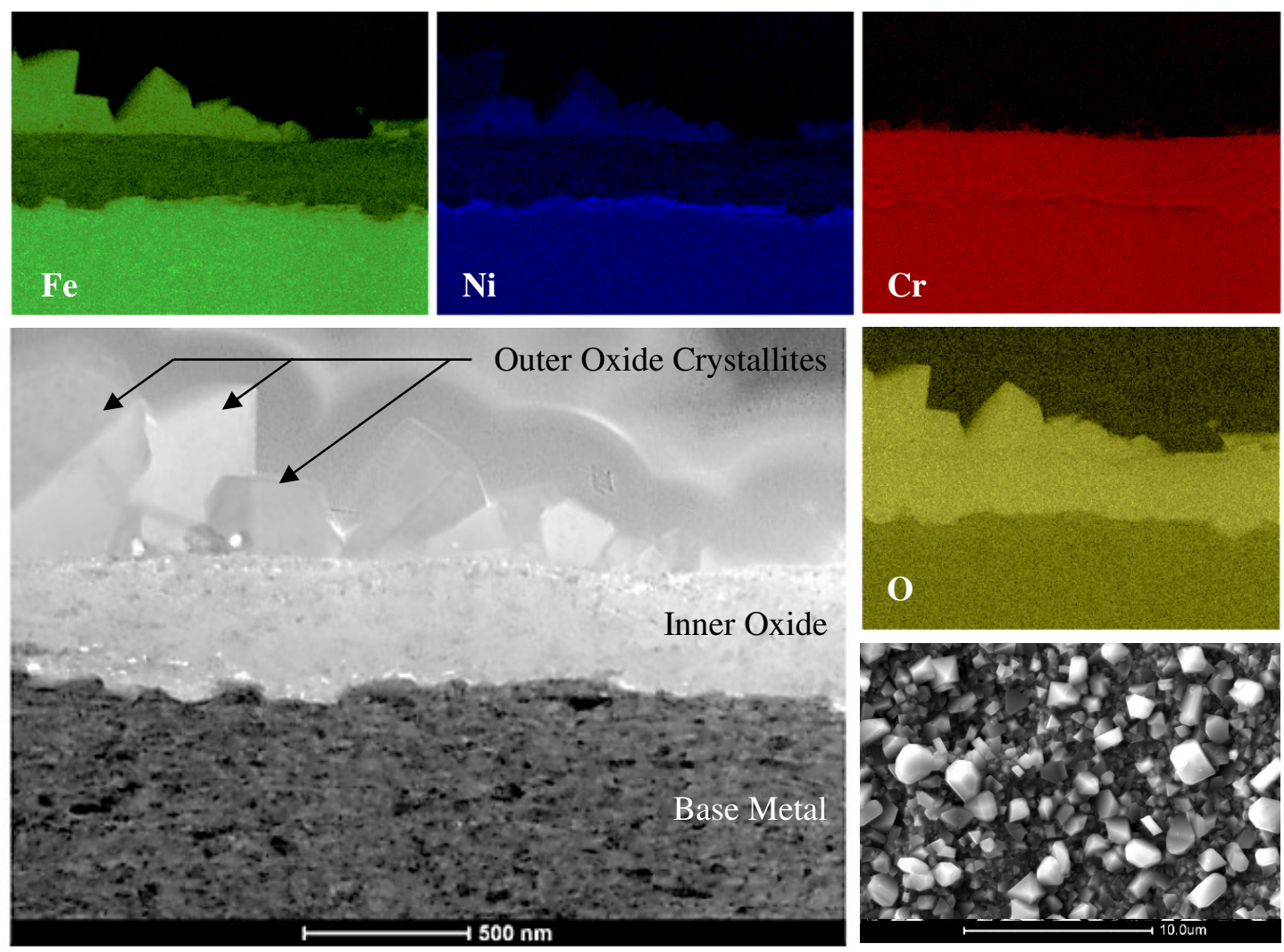

Figure 1. Scanning-transmission image and EDX elemental maps of base metal, inner oxide, and outer oxide crystallites in 317L stainless steel. Also shown is an SEM image of the crystallites on the corrosion surface. 